\title{
RESTOS ÓSEOS HUMANOS FRAGMENTADOS DEL CEMENTERIO INDÍGENA DE BARADERO. ALCANCES Y LIMITACIONES DE SU ESTUDIO BIOARQUEOLÓGICO.
}

\section{FRAGMENTED HUMAN SKELETAL REMAINS OF BARADERO INDIGENOUS CEMETERY. SCOPE AND LIMITATIONS OF THE BIOARCHAEOLOGICAL STUDY.}

\author{
Livia Kozameh르, Alicia Tapia², Manuel López ${ }^{3}$ y Nora Testa ${ }^{4}$ \\ ${ }^{1}$ Facultad de Humanidades y Artes, Universidad Nacional de Rosario. E-mail: \\ liviakozameh@gmail.com; \\ ${ }^{2}$ Facultad de Filosofía y Letras, Universidad de Buenos Aires; Dpto. de Ciencias Sociales, \\ Universidad Nacional de Luján. E-mail: aliciahtapia@yahoo.com.ar; \\ ${ }^{3}$ Facultad de Humanidades y Artes, Universidad Nacional de Rosario. E-mail: \\ manuz63@arnet.com.ar; \\ ${ }^{4}$ Facultad de Humanidades y Artes, Universidad Nacional de Rosario. E-mail: \\ traciates@hotmail.com
}

Presentado: 26/6/2014 - Aceptado: 18/4/2015

\section{Resumen}

Se analiza un conjunto de restos óseos humanos fragmentados correspondientes al sitio "Cementerio Indígena", ubicado en Baradero, Pcia. de Buenos Aires. Según las características de los materiales asociados a los enterratorios se atribuyó una cronología correspondiente a la primera mitad del siglo XVII; esta estimación temporal ha sido corroborada actualmente mediante dos fechados radiocarbónicos. El registro arqueológico se ha vinculado con la misión franciscana "Santiago del Baradero" que fundó Hernandarias en 1615. Entre los objetivos que se persiguen con este estudio se destacan: la revalorización de la información bioarqueológica que proporcionan los restos óseos fragmentados con características similares a las de un osario; y la relevancia que adquiere este registro dado que es único en su tipo y puede aportar conocimientos sobre el impacto de la empresa evangelizadora colonial en el área. Si bien el estudio bioarqueológico está limitado por la falta de integridad de las piezas esqueletales, rescatamos información sobre el número mínimo de individuos, edad, sexo, posibles patologías e indicadores de actividad más frecuentes. Asimismo, estimando un número mínimo de 19 individuos evaluamos indicadores de estrés nutricional y dieta mediante el análisis dentario. Discutimos su relación con el contexto sociocultural y los posibles cambios producidos por el conflicto interétnico.

Palabras clave: osario, reducción indígena, Bioarqueología, Arqueología Histórica 


\begin{abstract}
We analyze a collection of fragmentary human skeletal remains from "Cementerio Indígena" site, located in Baradero, Buenos Aires province. According to the materials characteristics that were found associated with burials, they was attributed to the first half of the seventeenth century and this estimation has been corroborated by two radiocarbon dates. The archaeological records has been associated with the "Santiago del Baradero" Franciscan mission, founded in 1615 by Hernandarias. Among the objectives pursued with this study we emphasize: the revalorization of bioarchaeological information which can provide the fragmentary bone remains with similar characteristics to those of an ossuary, and the relevance of this record, since it is only of its kind and may provide insights into the impact of colonial evangelization enterprise into the area. Although the bioarchaeological study is constrained by a lack of integrity of the cranial and postcranial skeletal pieces, we rescued information about the minimum number of individuals, age, sex, the possible pathologies indicators and the more frequent activities. Also, pondering a minimum of 19 individuals we assess indicators of nutritional stress and diet by dental analysis. We discuss its relationship with the sociocultural context and the possible changes brought about the interethnic conflict.
\end{abstract}

Keywords: ossuary, indigenous reduction, Bioarchaeology, Historical Archaeology

\title{
Introducción
}

El registro arqueológico que se analiza en este trabajo fue recuperado en el sitio Cementerio Indígena, ubicado sobre una barranca a $18 \mathrm{msnm}$ en la margen derecha del río Baradero ( $33^{\circ} 48^{\prime} 0.4^{\prime \prime} \mathrm{S}$ y $59^{\circ} 30^{\prime} 6.18^{\prime \prime} \mathrm{O}$ ), provincia de Buenos Aires (Figura 1). El sitio fue excavado por Salvador Debenedetti en 1910, quien en esa oportunidad exhumó 14 entierros asociados con varios tipos de hallazgos que formaban parte del ajuar funerario (Debenedetti 1911). Entre ellos se registraron materiales tanto de manufactura aborigen como de procedencia europea. En el primer caso se incluyen cuentas de collar de valva recortada y perforada, fragmentos de cerámica, discos y cuentas de latón ${ }^{1}$. En el segundo caso se registraron cuentas de vidrio, cascabeles, un anillo de material ferruginoso y muy escasos fragmentos de cerámica vidriada (Figura 2).

Por las características del registro arqueológico Debenedetti (1911) lo vinculó temporalmente con los momentos en que habría funcionado la misión franciscana de Santiago del Baradero. Esta se instaló en las cercanías del sitio a partir de 1615 como parte de las estrategias de control de la mano de obra y de evangelización de las poblaciones nativas entre las que se encontraban guaraníes, chanás y mbeguás. Para la misma fecha se fundaron dos reducciones más en el ámbito del Río de La Plata (San José del Bagual y Tubichaminí), pero mientras estas tuvieron una existencia efímera la misión Santiago del Baradero fue la única que perduró en el tiempo, desde 1615 hasta 1756 cuando pasó a designarse catastralmente como un pueblo de criollos (Barbich 2007). Las fuentes documentales disponibles en el Archivo General de Indias (AGI), Audiencia de Charcas $(\mathrm{ACH})$, sobre el origen y evolución de la reducción Santiago del Baradero 
durante el siglo XVII refieren alzamientos indígenas, enfrentamientos armados, la situación de los nativos y la existencia de enfermedades endémicas (AGI-ACH 1606, 1609, 1610, 1613, 1616, 1617, 1618, 1619/1620, 1622, 1628, 1664, 1678, 1679, 1690, 1691, 1694). Para los primeros años del funcionamiento de dicha reducción, las referencias indican que la vida fue muy difícil, tanto para los aborígenes como para los franciscanos: hambrunas, epidemias y elevada mortalidad fueron situaciones frecuentes desde los primeros momentos:

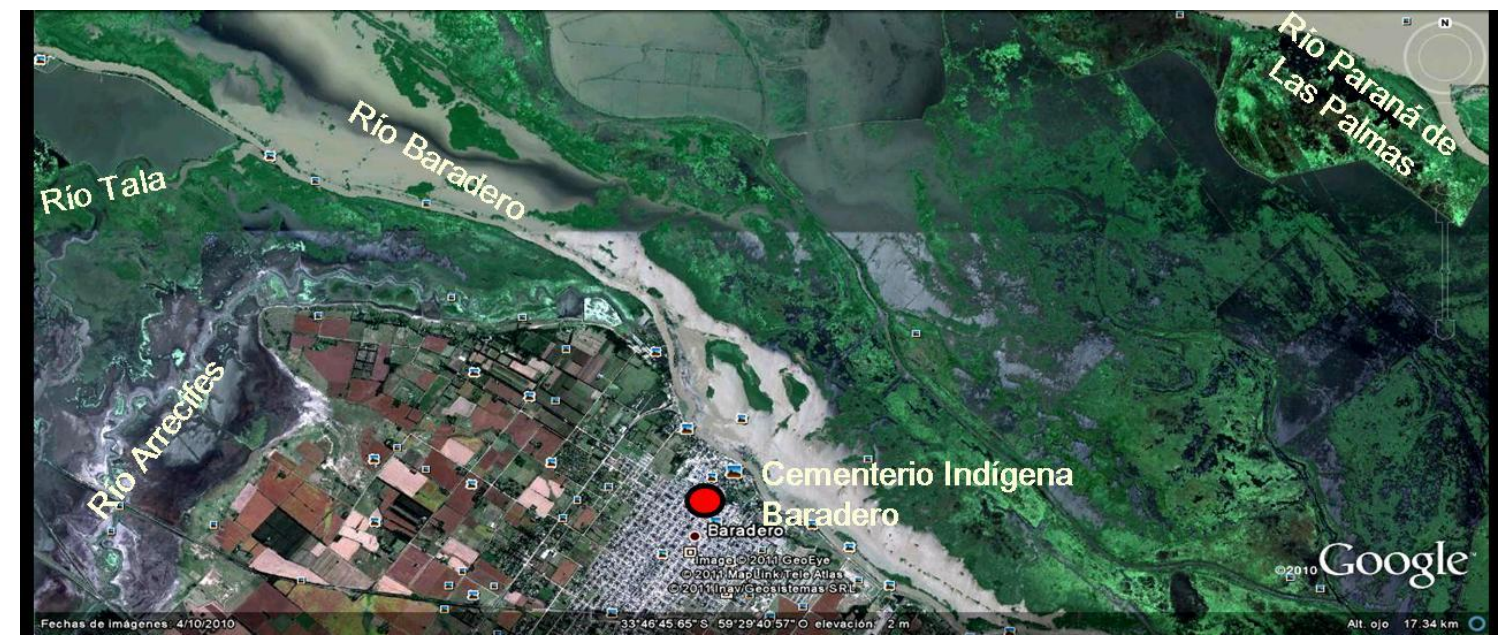

Figura 1. Ubicación del sitio arqueológico Cementerio Indígena en la ciudad de Baradero.

"viven como de milagro sustentándose con caza y pesquería y que en ninguna manera les pueden dar a los sacerdotes que los doctrinan para su sustento (AGIACH 1619/1620, Legajo 147: pág. 6).

"entro en la reducción de Baradero... los indios habianse muerto de peste más de 60 y otros se habían ausentado por el temor de ella" (AGI, ACH, 1622, Legajo No 27: pág. 14).

El análisis realizado de los documentos escritos y los materiales arqueológicos recuperados en el sitio Cementerio Indígena permiten relacionar ambos tipos de registro. En efecto, mediante la obtención de dos fechados radiocarbónicos realizados sobre material óseo, en la actualidad hemos podido corroborar la atribución cronológica que realizó Debenedetti a comienzos del siglo XX. Los fechas obtenidas indican la existencia de al menos dos eventos de enterratorio diferenciados: la datación más temprana es de $420 \pm 50$ años C14 AP (Latyr LP- 2408, hueso, cal. DC 1577 a 1621) y la más reciente es de $230 \pm 50 \mathrm{C}^{14} \mathrm{AP}$ (Latyr LP- 2424, hueso, cal. DC 1643 a 1696). Por lo tanto, se trata de un registro arqueológico que temporalmente se ubicaría dentro de un rango aproximado de los primeros cuarenta a ochenta años de instalada la reducción Santiago del Baradero. 


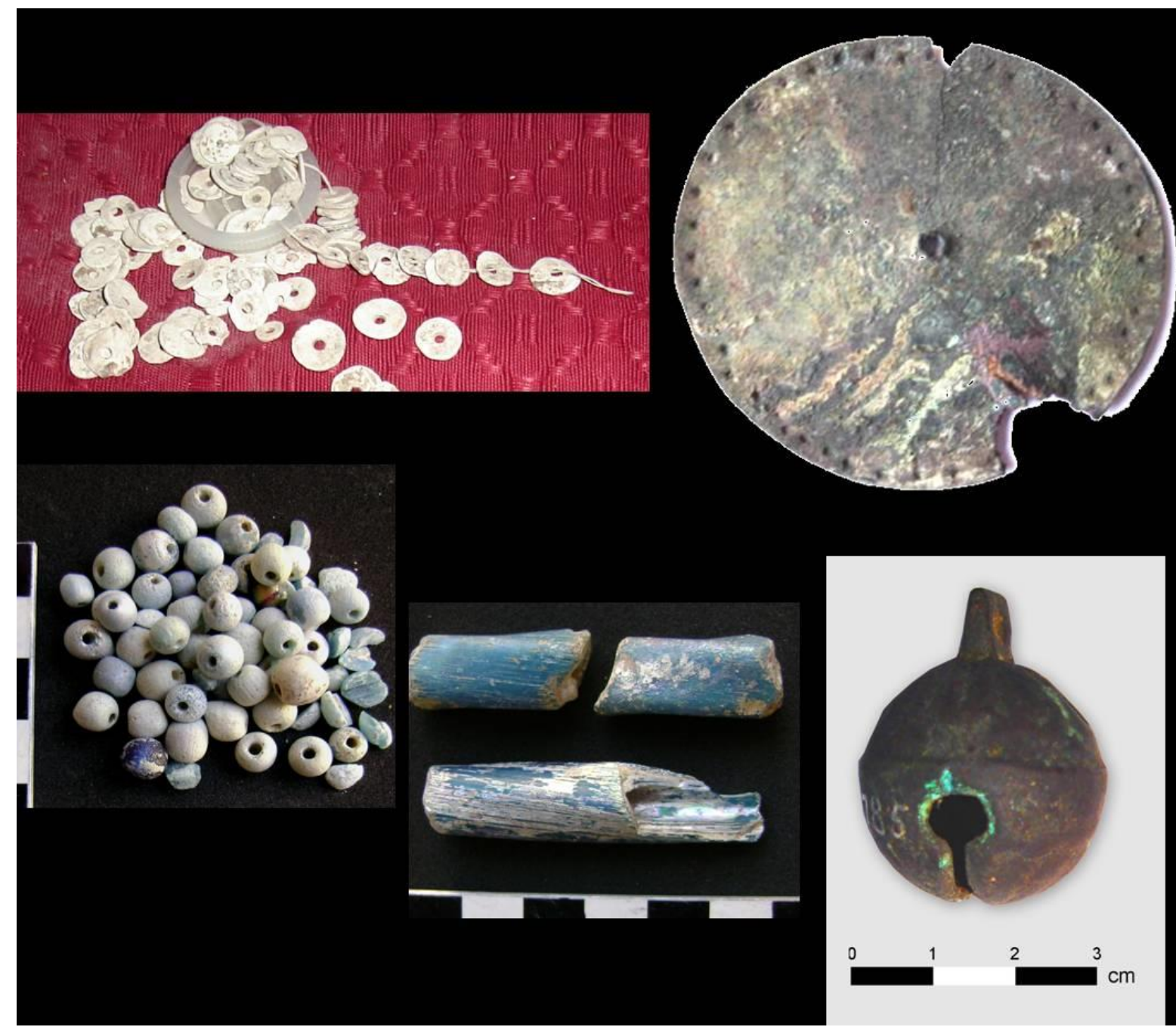

Figura 2. Materiales del ajuar funerario. Arriba: cuentas de valva recortada y disco de latón con decoración realizada con punzonado perimetral. Abajo: cuentas de vidrio turquesa esféricas medianas y Nueva Cádiz y cascabel de bronce.

Desde la excavación pionera de Debenedetti hasta hace unos pocos años atrás, se fueron sucediendo perturbaciones en el sitio Cementerio Indígena debido a la acción de coleccionistas, la apertura de calles laterales y el relleno de un sector del terreno. Estas actividades de remoción afectaron en gran medida la posibilidad de ampliar las excavaciones en la actualidad, además de las dificultades que se plantean con los reclamos de los pueblos originarios ${ }^{2}$. A partir de 2006 las autoridades municipales de la ciudad de Baradero iniciaron actividades de valorización del sitio como patrimonio histórico de la ciudad y, de acuerdo con el interés de la comunidad, se han llevado a cabo varios proyectos de investigación arqueológica y puesta en uso social del predio como museo de sitio $^{3}$. Entre otros objetivos se busca poner en valor el registro arqueológico que forma parte de las colecciones depositadas en el Museo A. Barbich de esa localidad. 
La planificación de tales actividades se ha realizado con el consenso previo de las asociaciones de pueblos originarios del área.

Hasta el momento se emprendieron estudios en el terreno con georradar para determinar la posible extensión del área de enterratorios y se efectuó el relevamiento de perfiles estratigráficos en sectores removidos, la recolección de muestras sedimentarias y de restos orgánicos con resolución estratigráfica precisa para efectuar dataciones radiocarbónicas. Por otra parte se avanzó con el estudio de los diferentes materiales de metal y de las cuentas de vidrio europeas que integran las colecciones del sitio (Tapia y Pineau 2011, 2013; Tapia et al. 2009). Una vía de análisis recientemente iniciada consiste en determinar a través del ADN mitocondrial (mt) antiguo los siguientes aspectos: el parentesco entre los individuos identificados, la distancia genética entre los grupos nativos migrantes y su contribución al acervo genético local (Cardozo et al. 2014). Se parte de la premisa que el ADNmt de la mayoría de las poblaciones amerindias pertenece a los haplogrupos o linajes A, B, C, D y X. Mientras que el X solo se encuentra en Norteamérica donde prevalece el A, en Sudamérica se ha identificado el C y D, especialmente en el área litoral atlántica, y el B en el área andina. Hasta el momento se han analizado 21 muestras (que incluyen restos óseos y dentarios) con diferentes técnicas de extracción, identificando tres casos del haplogrupo A, cuatro del B y uno del D (Cardozo et al. 2013).

Por otra parte, se analizaron diferentes fuentes documentales que refieren aspectos de la fundación de las misiones franciscanas en el área, el número de aborígenes, epidemias, hambrunas, exigencias del pago de tributos, movilidad y relocalización de los grupos de diferentes etnias, dificultades del adoctrinamiento, materiales de las viviendas, forma de subsistencia, vestimenta y herramientas de labranza, entre otros datos. Esta información histórica constituye un importante recurso metodológico para la correlación con las interpretaciones del registro arqueológico obtenido en el sitio Cementerio Indígena.

En este trabajo se presentan los resultados del estudio de la colección de restos óseos que se encuentran depositados en el Museo A. Barbich, Baradero, provincia de Buenos Aires. Nuestro propósito es aportar información sobre la forma de vida y las consecuencias culturales y biológicas que se produjeron a partir de la instalación de las primeras misiones en el Río de La Plata, problemáticas muy poco conocidas arqueológicamente. Si bien en el marco de investigaciones arqueológicas previas, Kozameh y Barbosa analizaron once piezas maxilares cuyos resultados ya fueron publicados (Tapia 1999, 2002), en el estudio que aquí se presenta se incluyen nuevas piezas dentarias y la totalidad de los restos óseos que integran la colección que procede del sitio. Se trata de una muestra integrada por piezas que ingresaron a la colección 
general a partir de donaciones efectuadas por vecinos de la localidad en diferentes momentos, y que en su mayoría están muy fragmentadas. A pesar de estas condiciones de hallazgo se considera de interés revalorizar la información que puede proporcionar este "osario" o conjunto de piezas óseas humanas, dado que constituyen la única muestra disponible para este tipo de asentamientos coloniales en el área.

En cuanto a los aportes relativos que puede ofrecer el análisis de los osarios, varios investigadores han señalado su utilidad, indicando en tal sentido un cambio en el paradigma tradicional, dado que se tendía a priorizar la recuperación de los huesos craneales y los huesos largos completos, mientras que se dejaban en el terreno los restos óseos muy fragmentados (tal como lo hizo Debenedetti en 1910 durante la excavación del Cementerio Indígena). Entre otros investigadores, Luna (2002) señala que a partir de mediados del siglo XX se observa un mayor interés por investigar las condiciones estratigráficas de los hallazgos, así como también por integrar los restos óseos humanos completos con los fragmentados y con los demás elementos asociados del registro arqueológico.

Entre otros estudios de restos óseos humanos fragmentados y de osarios que realizaron investigadores extranjeros se destaca el de Ubelaker (1974), quien a través del análisis de varios conjuntos de fragmentos óseos logró describir el perfil de la población correspondiente al arcaico Woodland tardío de Maryland. También Ubelaker y Ripley (1999) analizaron varios grupos de osarios encontrados en la iglesia de San Francisco, en Quito (Ecuador), que les permitieron reconocer la presencia de al menos 226 individuos enterrados en ese predio. Por otra parte, McKinley (2004a, 2004b) tuvo en cuenta los restos desarticulados, entremezclados (co-mingled) y cremados al elaborar las normas para el inventario de la Guidelines to the Standards for Recording Human Remains, indicando de esta manera el valor potencial que ofrece el estudio de los fragmentos óseos humanos, aún en el caso de los que se encuentran altamente perturbados por cremación. En nuestro país cabe citar el análisis que realizaron Baffi y Torres (1995-96) a partir de los fragmentos óseos del sitio Martínez 4, en Ambato (Catamarca), y de Luna (2002, 2008) en el sitio Chenque 1 (Lihué Calel, La Pampa), con resultados de interés para la caracterización demográfica, de edad, sexo y patologías, entre otros aspectos, de las poblaciones prehispánicas de cada área.

De acuerdo a los alcances que presenta el análisis bioarqueológico de los fragmentos óseos, los objetivos planteados en este trabajo se orientan a obtener información sobre: 1) la acción de los agentes naturales y culturales post-depositacionales que habrían intervenido en la formación del registro arqueológico; 2) los elementos anatómicos que componen la muestra; 3) la determinación del número mínimo de individuos; 4) estimación de edad y determinación del sexo; 5) posibles patologías; 6) rastros que indiquen actividades frecuentes; y 7) indicadores de estatus nutricional y dieta, especialmente aquellos registrados en las piezas dentales. Por último, a través de la 
información obtenida en cada uno de estos aspectos, nos proponemos aportar nuevos datos a la discusión sobre el impacto biológico y cultural producido por el conflicto interétnico en las poblaciones nativas del área, que a juzgar por las fuentes documentales fueron inicialmente guaraníes y chanáes (AGI-ACH, 1619/1620, 1622, 1628).

\section{Materiales y métodos}

El análisis de las 710 piezas óseas que componen la muestra se realizó en el Gabinete del Departamento de Bioantropología y Evolución, Facultad de Humanidades y Artes de la Universidad Nacional de Rosario. En primer lugar, teniendo en cuenta las características fragmentarias del registro arqueológico disponible, se identificaron los elementos anatómicos y se estableció el número mínimo de individuos a partir de los huesos maxilares y mandibulares. En los casos en que la condición de la muestra lo permitió se efectuaron estimaciones de edad y determinación del sexo. No fue posible realizar estimaciones sobre la estatura dada la ausencia de huesos largos completos.

En segundo lugar se analizaron las piezas óseas en búsqueda de rastros que indicaran cotidianidad de actividades, tipo de dieta, estatus nutricional y posibles patologías. Para el caso de las piezas dentarias se tuvo en cuenta los marcadores de estrés nutricional, tales como hipoplasias, caries y pits en el esmalte y se aplicaron los criterios de desgaste dental de Brothwell (1993) como variable relativa de estimación de la edad de los individuos. Si bien tales criterios son controvertidos, dado que en las poblaciones cazadoras-recolectoras el desgaste de las superficies oclusales está influenciado por el tipo de dieta y los resultados presentan diferentes grados de confiabilidad (Mays et al. 1995; Santini et al. 1990), se decidió utilizarlo ya que tratándose de un osario no se contó con otros estimadores etarios, como por ejemplo las suturas craneales. Para caracterizar el estado de salud bucal de los individuos identificados se tuvieron en cuenta tres variables de análisis y sus correlaciones: 1) las alteraciones en la amelogénesis; 2) las infecciones alveolares; y 3) el número de piezas perdidas en vida (PIV).

El registro y análisis de los diferentes restos óseos se realizó de acuerdo con los criterios que se especifican en diversas obras y manuales de osteología, tales como Brothwell (1993), Buikstra y Ubelaker (1994) y White y Folkens (1991). Para el estudio de los fragmentos óseos de un individuo perinato se aplicaron los estándares de osteología fetal definidos por Fasekas y Kósa (1978). La discusión sobre la presencia de un tipo de rasgo epigéntico -identificado en tres huesos craneales de la muestra- se apoyó en las argumentaciones que han desarrollado Neves (1988) y Pezo Lanfranco et al. (2009), entre otros investigadores. En cuanto a los procesos tafonómicos que habrían actuado modificando algunos aspectos de la muestra se analizaron aspectos tales como las alteraciones producidas por la meteorización (sensu Behrensmeyer 1978), las marcas de carnívoros y de corte (sensu Blumenschine et al. 1996), las manchas de objetos metálicos y de ocre. 


\section{Alteraciones producidas por agentes naturales y antrópicos}

La colección de materiales óseos humanos que se analiza se fue configurando con el aporte que en diferentes momentos efectuaron dos tipos de donantes; el de algunos vecinos que extrajeron materiales del Cementerio Indígena de manera asistemática y los que obtuvo Daniel Conlazo a partir de la excavación que realizó en 1984 (según la información que dejó registrada en la ficha museográfica de ingreso de la colección al Museo A. Barbich). En esa oportunidad realizó una intervención arqueológica en el sitio, específicamente en los alrededores de los cimientos de una vivienda ya derruida. Es en este sector donde exhumó un conjunto de restos óseos que estaban asociados y correspondían a los restos de un individuo femenino y a un nonato bastante deteriorados y con escasa articulación (Conlazo 1984). De la misma manera que los enterratorios que describió Debenedetti, en este caso el ajuar funerario también estaba formado por cuentas de collar de valva y de vidrio europeas y varios fragmentos de discos perforados de latón.

Como los materiales no fueron tratados para su preservación, desde que fueron extraídos del sedimento estuvieron sujetos a la alternancia de acciones de remoción (entierro y desentierro) o a condiciones poco favorables de humedad y acción de insectos en su lugar de depósito. Por estos motivos resulta de interés evaluar la alteración que podrían haber producido los agentes postdepositacionales, tanto naturales como antrópicos.

La distribución de los grados de meteorización registrada en la muestra que se expresa en la Tabla 1, indica que los agentes ambientales postdepositacionales (radiación solar, humedad, temperaturas variables, etc.) incidieron en el $50 \%$ de la muestra; en especial, se destacan los procesos que produjeron agrietamientos $(48 \%)$ y astillamientos (39\%) en algunos sectores de los huesos.

Esto indicaría que, al menos por un tiempo, algunas piezas permanecieron desenterradas y fueron sometidas a factores atmosféricos. Esta situación puede correlacionarse con la presencia de marcas de carnívoros en al menos tres huesos largos fragmentados (dos tibias y un fémur). Tales marcas tienen una sección con forma en $U$, de $3 \mathrm{~mm}$ de profundidad y un canal de $5 \mathrm{~mm}$ de espesor, similar al ancho que presentan los colmillos de Canis familiares de gran porte (Figura 3). Probablemente estas marcas fueron realizadas a posteriori del desentierro, dado que son más frescas que la pátina que actualmente presenta el hueso. La misma situación se observa en el caso del único hueso que presenta marcas o huellas de corte, que por su morfología condice con el uso de herramientas de excavación tales como azadones o palas y, por lo tanto, podría ser el efecto de las remociones asistemáticas. 


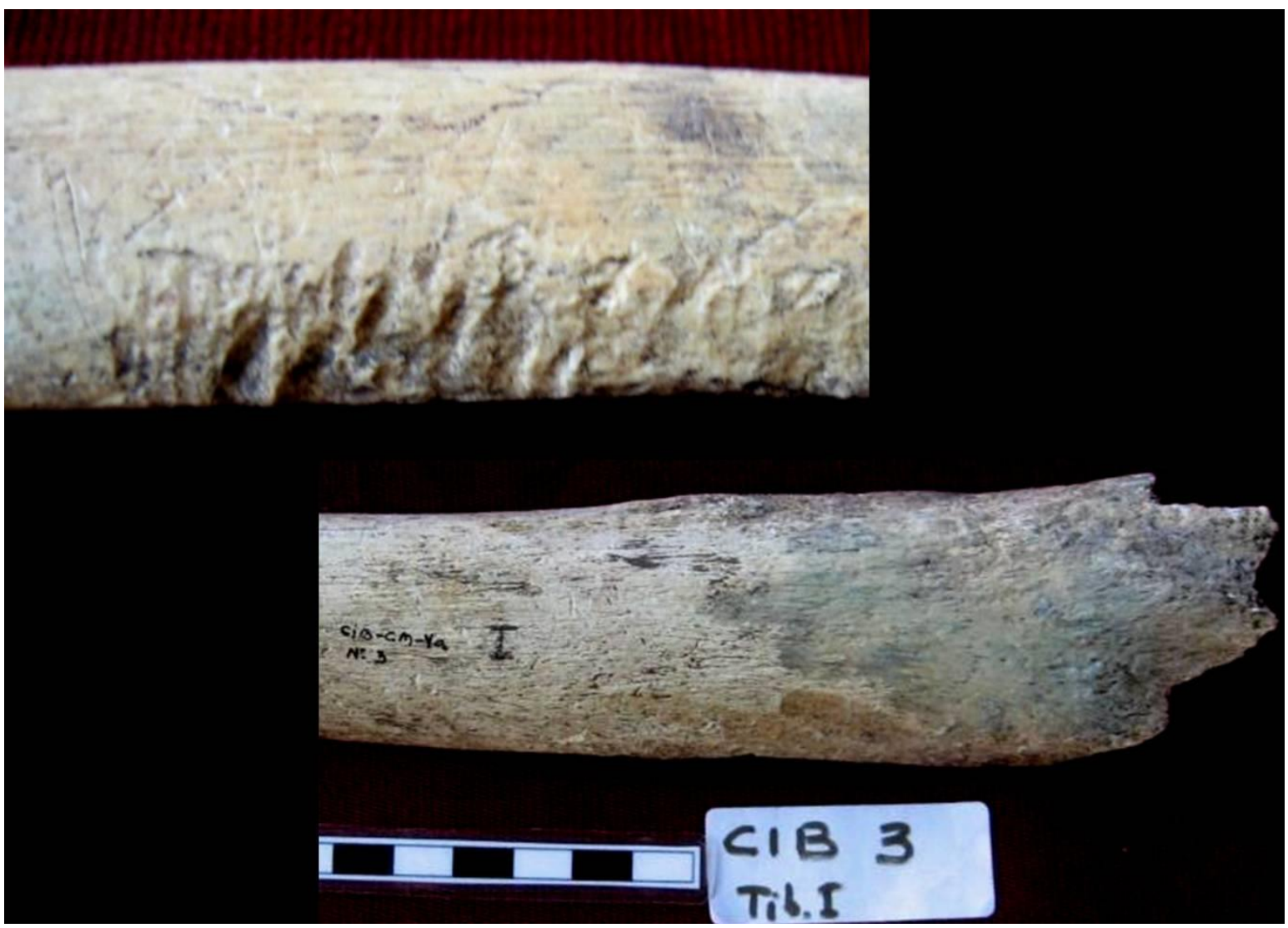

Figura 3. Agentes post-depositacionales. Arriba: marcas de carnívoro sobre epífisis de hueso largo. Abajo: hacia la derecha el fragmento de epífisis de tibia presenta manchas verdosas producidas por la oxidación de materiales de latón.

\begin{tabular}{|l|c|c|}
\hline Índices de meteorización & $\begin{array}{c}\text { Cantidad } \\
\text { por índice }\end{array}$ & $\%$ \\
\hline 1- Fisura a la estructura fibrosa & 3 & 0,8 \\
\hline 2- Descascaramientos y exfoliación de capas externas & 6 & $1,6 \%$ \\
\hline 3 -Aspecto fibroso con agrietamiento (Prof 1 - 1,5 cm.) & 38 & $10,6 \%$ \\
\hline 4- Agrietamientos profundos con astillamientos & 171 & $48 \%$ \\
\hline 5 - Astillamientos extensivos y destrucción in situ & 139 & $39 \%$ \\
\cline { 1 - 2 } Total de piezas con proceso de meteorización & 357 & \\
\cline { 1 - 2 } Frecuencia en el total de la muestra (N=710) & $50 \%$ & \\
\cline { 2 - 3 } Tabla 1. Frecuencia de piezas con diferentes grados \\
de meteorización (Behrensmeyer 1978).
\end{tabular}

Aunque el número de piezas en las que se han encontrado manchas de color verdoso y de ocre es muy escaso, su presencia es muy significativa por cuanto se asocian con las prácticas rituales mortuorias de los grupos nativos del área. En el primer caso, las manchas se encuentran sobre partes de una tibia y de una escápula, y son el producto de la oxidación de los objetos metálicos que fueron parte de los adornos corporales y de la 
vestimenta de los individuos enterrados (Figura 3). El análisis de los componentes minerales y de la microestructura de esos materiales ha demostrado que se trata de latón, materia prima que presenta un alto contenido de cobre (65 a $70 \%$ ) y de zinc ( 25 a $30 \%$ ) entre otros minerales (Tapia et al. 2009). Este tipo de formaciones corrosivas sobre el hueso también se ha reportado en otros sitios arqueológicos con hallazgos de adornos de latón similares (Salgán et al. 2012) y en los estudios de objetos confeccionados con aleaciones de cobre en los que se observa la formación de óxido cuproso recubierto con carbonatos hidratados, como la malaquita (verde) y la azurita (azul). De acuerdo a las condiciones del suelo, esos dos últimos minerales suelen entremezclarse con sulfatos, cloruros y sulfuros (Pifferetti 2001).

\section{Análisis de la muestra}

Teniendo en cuenta los datos obtenidos sobre el estado de integridad de la muestra (Tabla 2), se observa una distribución muy baja de piezas anatómicamente completas $(3 \%)$, siendo más numerosos en primer lugar los fragmentos craneales y poscraneales anatómicamente determinables $(53 \%) \mathrm{y}$, en segundo lugar, los fragmentos anatómicamente no determinables $(42 \%)$. En general las piezas más fragmentadas son las de mayor tamaño como los huesos largos, aunque también son muy abundantes los fragmentos craneales. Por el contrario, las escasas piezas completas que se identificaron corresponden a huesos de menor tamaño tales como metacarpos, metatarsos, astrágalo, navicular, rótula y malar. Las piezas dentarias sueltas, que no están incluidas en los fragmentos maxilares o mandibulares, también tienen una representación muy baja.

\begin{tabular}{|c|c|c|c|c|c|}
\hline \multirow{2}{*}{$\begin{array}{c}\text { Piezas } \\
\text { poscraneales } \\
\text { completas }\end{array}$} & \multirow{2}{*}{$\begin{array}{c}\text { Fragmentos } \\
\text { craneales y } \\
\text { postcraneales } \\
\text { anatómicamente } \\
\text { determinables }\end{array}$} & $\begin{array}{c}\text { Fragmentos } \\
\text { anatómicamente } \\
\text { no determinables }\end{array}$ & \multicolumn{2}{|c|}{$\begin{array}{c}\text { Piezas Dentarias } \\
\text { sueltas }\end{array}$} & Total \\
\cline { 1 - 3 } & 377 & 305 & 7 & 1 & 710 \\
\hline $3 \%$ & $53 \%$ & $42 \%$ & $1 \%$ & $0,1 \%$ & \\
\hline
\end{tabular}

Tabla 2. Distribución del total de la muestra discriminada en cuatro categorías según el estado de las piezas.

Para el caso de las piezas craneales, salvo la presencia de una calvaria, un malar, dos maxilares y dos mandíbulas que están completas, los huesos que integran el neurocráneo como el esplacnocráneo se encuentran muy fragmentados. Tal como se expresa en Tabla 3 , el total de fragmentos craneales ascienden a 219 , de los cuales es muy elevada la frecuencia de los fragmentos no determinables (70\%), en tanto que aquellos cuyos rasgos permiten adjudicarlos a un hueso craneal en particular tienen una frecuencia menor 
$(27 \%)$. Lamentablemente por la marcada fragmentación que presentan no resulta posible identificar el NMI considerando su lateralidad.

\begin{tabular}{|c|c|c|c|c|}
\hline \multirow{4}{*}{$\begin{array}{c}\text { PIEZAS CRANEALES } \\
\text { COMPLETAS }\end{array}$} & calvaria & 1 & \multirow{4}{*}{6} & \multirow{4}{*}{$3 \%$} \\
\hline & malar & 1 & & \\
\hline & maxilar & 2 & & \\
\hline & mandíbula & 2 & & \\
\hline \multirow{9}{*}{$\begin{array}{l}\text { FRAGMENTOS } \\
\text { CRANEALES } \\
\text { DETERMINABLES }\end{array}$} & temporal & 9 & \multirow{9}{*}{60} & \multirow{9}{*}{$27 \%$} \\
\hline & frontal & 7 & & \\
\hline & parietal & 22 & & \\
\hline & occipital & 10 & & \\
\hline & esfenoide & 1 & & \\
\hline & etmoides & 1 & & \\
\hline & malar & 1 & & \\
\hline & maxilar & 5 & & \\
\hline & mandíbula & 4 & & \\
\hline \multicolumn{2}{|c|}{$\begin{array}{l}\text { FRAGMENTOS CRANEALES NO } \\
\text { DETERMINABLES }\end{array}$} & \multicolumn{2}{|c|}{153} & $70 \%$ \\
\hline & \multicolumn{2}{|c|}{ Total de piezas craneales } & 219 & \\
\hline
\end{tabular}

Tabla 3. Distribución de piezas craneales según criterios de integridad y de identificación anatómica.

En la Tabla 4 se cuantifican los restos óseos considerando tanto la frecuencia de las piezas craneales y poscraneales -completas y fragmentadas- como la lateralidad, en los casos en que se pudo identificar. Teniendo en cuenta este criterio se identificó un NMI de cinco individuos por la presencia de cúbitos derechos, cuatro por húmeros izquierdos como así también por fémures y tibias derechos.

En esta cuantificación no se incluyen los restos óseos de un individuo nonato/perinato, dado que por su integridad el conjunto de piezas anatómicas representadas se analiza de manera separada. Para su análisis se aplicaron los estándares de osteología fetal definidos por Fasekas y Kósa (1978). Las piezas utilizadas como elemento diagnóstico para estimar la edad fueron la séptima costilla izquierda, dos fragmentos de escápula y la tibia izquierda (Figura 4). Según las medidas registradas en el largo y ancho de estas piezas, se calcula que el individuo habría tenido aproximadamente entre siete y ocho meses y medio de vida intrauterina al momento de su muerte. 


\begin{tabular}{|c|c|c|c|c|c|c|}
\hline \multirow{2}{*}{\multicolumn{2}{|c|}{$\begin{array}{c}\text { Pieza anatómica } \\
\text { (No se incluyen los restos de } \\
\text { un individuo perinato) }\end{array}$}} & \multicolumn{2}{|c|}{ Estado de integridad } & \multicolumn{3}{|c|}{ Lateralidad } \\
\hline & & Completas & $\begin{array}{l}\text { Fragmento/s } \\
\text { determinable/s }\end{array}$ & Derecha & Izquierda & $\mathrm{N} / \mathrm{D}$ \\
\hline \multicolumn{2}{|c|}{ Maxilar } & 2 & 5 & 2 & - & 3 \\
\hline \multicolumn{2}{|c|}{ Mandíbula } & 1 & 4 & 1 & - & 3 \\
\hline \multicolumn{2}{|c|}{ Vértebra } & 1 & 6 & - & - & - \\
\hline \multicolumn{2}{|c|}{ Costillas } & 1 & 22 & 1 & - & 21 \\
\hline \multicolumn{2}{|c|}{ Clavícula } & - & 1 & - & 1 & - \\
\hline \multicolumn{2}{|c|}{ Escápula } & - & 3 & - & 3 & - \\
\hline \multicolumn{2}{|c|}{ Húmero } & - & 4 & - & 4 & - \\
\hline \multicolumn{2}{|c|}{ Radio } & - & 4 & 1 & 3 & - \\
\hline \multicolumn{2}{|c|}{ Cúbito } & - & 6 & 5 & - & 1 \\
\hline \multicolumn{2}{|c|}{ Fémur } & - & 23 & 4 & 3 & 16 \\
\hline \multicolumn{2}{|c|}{ Rótula } & 1 & 1 & 2 & - & - \\
\hline \multicolumn{2}{|c|}{ Tibia } & - & 16 & 4 & 3 & 9 \\
\hline \multicolumn{2}{|c|}{ Peroné } & - & 3 & 2 & - & 1 \\
\hline \multicolumn{2}{|c|}{ Carpo } & - & 1 & 1 & - & - \\
\hline \multicolumn{2}{|c|}{ Metacarpo } & 4 & 9 & 1 & 9 & 3 \\
\hline \multicolumn{2}{|c|}{ Falange } & - & 6 & - & 3 & 3 \\
\hline \multicolumn{2}{|c|}{ Tarso: calcáneo } & 4 & - & 1 & 3 & - \\
\hline \multicolumn{2}{|c|}{ Metatarsos } & 2 & 3 & 4 & 1 & - \\
\hline \multirow{5}{*}{ Coxal } & Fragmentos coxales & - & 3 & - & - & 3 \\
\hline & Escotadura ciática & - & 2 & - & - & 2 \\
\hline & Rama isquipúbica & - & 1 & - & - & 1 \\
\hline & $\begin{array}{l}\text { Isquión c/coxal y } \\
\text { acetábulo }\end{array}$ & - & 1 & 1 & - & - \\
\hline & $\begin{array}{l}\text { Illion superficie } \\
\text { articular }\end{array}$ & - & 1 & 1 & - & - \\
\hline \multicolumn{2}{|r|}{ Subtotales } & 16 & 125 & 31 & 33 & 66 \\
\hline
\end{tabular}

Tabla 4. Frecuencia de las piezas craneales y poscraneales completas y fragmentadas y su relación con la lateralidad.

\section{Características de la muestra dentaria}

El análisis de los maxilares, las mandíbulas y las piezas dentales ha proporcionado mayor información que los restos óseos fragmentados, ya que por su estado de conservación se pudo determinar un NMI de 19 individuos. En la Tabla 5 se contempla la edad, el sexo, la porción anatómica representada, el estado de los maxilares donde se consignan las piezas presentes, las piezas perdidas en vida (PIV), las piezas perdidas postmortem (PIM) y las piezas fragmentadas. Dentro de las patologías dentarias se incluyen las caries oclusales y de cuello o radiculares, las infecciones alveolares y las alteraciones amelogenéticas (hipoplasias y pitting) ${ }^{4}$. Entre los rasgos fisiológicos del aparato masticatorio se analizaron los desgastes y sus grados de intensidad (mínimo, 
mediano e intenso). Teniendo en cuenta las piezas maxilares y dentarias se efectuó la estimación de las franjas etarias representadas en la muestra. Del total de 19 individuos, cuatro corresponden a adultos maduros (uno de los cuales se determinó por el desgaste dentario), 12 son adultos, dos sub-adultos (identificados por la dentición decidua) y, finalmente, a partir de un fragmento de mandíbula se pudo identificar a un niño de cuatro años aproximadamente (Ubelaker 1974; White y Folkens 1991).

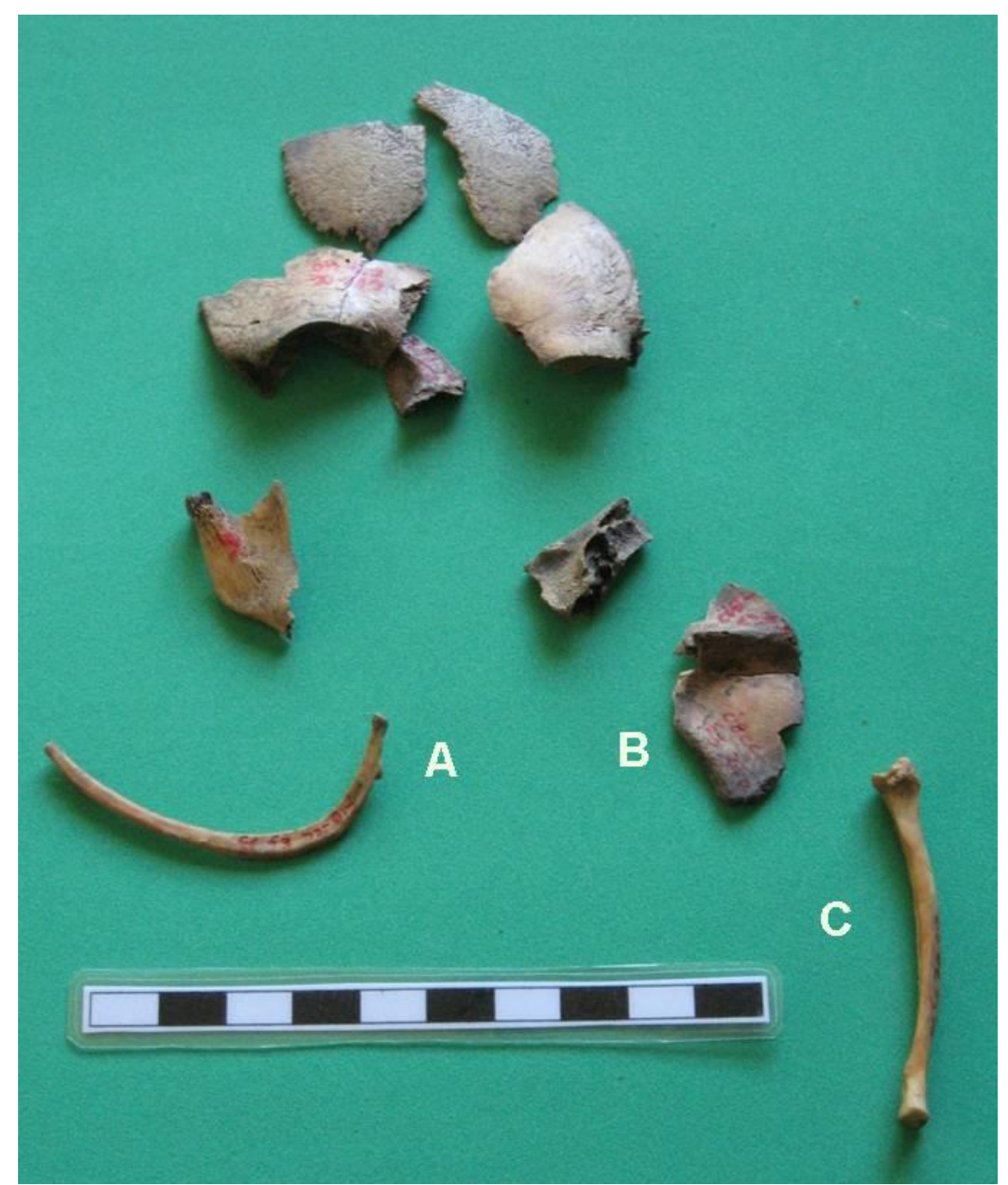

Figura 4. A) Séptima costilla izquierda; B)dos fragmentos de escápula; y C) tibia izquierda

Respecto de la presencia-ausencia de alteraciones amelogenéticas, en primer lugar es de destacar que 12 individuos (63\%) presentan piezas con bandas, pits y líneas de hipoplasias, en tanto que solamente dos (11\%) no las presentan (Gráfico 1). En segundo lugar las piezas con infecciones alveolares no son frecuentes en la muestra; solo se observan indicios de procesos infecciosos que habrían afectado la masa ósea en tres elementos anatómicos (16\%), tanto en un maxilar como en dos mandíbulas (Gráfico 2). Resulta de interés señalar que estas piezas con lóculos de infección alveolar también se asocian con la pérdida de piezas dentarias en vida (Gráfico 3). 


\begin{tabular}{|c|c|c|c|c|c|c|c|c|c|c|c|c|c|}
\hline \multirow{2}{*}{$\mathrm{N}^{\circ}$} & \multirow{2}{*}{ Edad } & \multirow{2}{*}{ Sexo } & \multirow[b]{2}{*}{$\begin{array}{l}\frac{\pi}{\pi} \\
\frac{\pi}{\Sigma} \\
\Sigma\end{array}$} & \multirow[b]{2}{*}{ 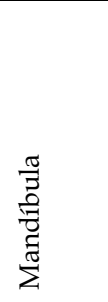 } & \multicolumn{4}{|c|}{$\begin{array}{l}\text { Piezas dentarias } \\
\text { Presentes }\end{array}$} & \multicolumn{2}{|c|}{ Piezas con caries } & \multirow{2}{*}{ 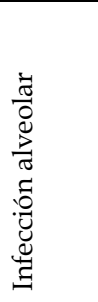 } & \multirow[b]{2}{*}{ 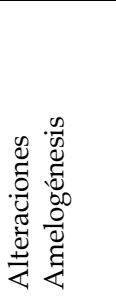 } & \multirow[b]{2}{*}{ 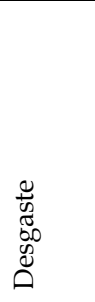 } \\
\hline & & & & & $\mathrm{N}^{\circ}$ & PIV & PIM & 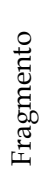 & $\begin{array}{l}\overline{\widetilde{J}} \\
\tilde{0} \\
\bar{U} \\
0\end{array}$ & 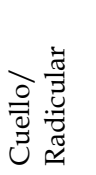 & & & \\
\hline 1 & 4 años & $\mathrm{N} / \mathrm{D}$ & - & $\begin{array}{l}\text { Frag. } \\
\text { ant. }\end{array}$ & 2 & - & 9 & - & $\mathrm{N} / \mathrm{D}$ & $\mathrm{N} / \mathrm{D}$ & $\mathrm{N} / \mathrm{D}$ & $\mathrm{N} / \mathrm{D}$ & $\mathrm{N} / \mathrm{D}$ \\
\hline 2 & adulto & $\mathrm{N} / \mathrm{D}$ & - & $1 / 2$ der. & - & - & 4 & - & $\mathrm{N} / \mathrm{D}$ & $\mathrm{N} / \mathrm{D}$ & - & $\mathrm{N} / \mathrm{D}$ & $\mathrm{N} / \mathrm{D}$ \\
\hline 3 & $\begin{array}{l}\text { adulto/ } \\
\text { maduro }\end{array}$ & $\mathrm{N} / \mathrm{D}$ & Comp. & - & - & - & 5 & 10 & $\mathrm{~N} / \mathrm{D}$ & $\mathrm{N} / \mathrm{D}$ & 1 & $\mathrm{~N} / \mathrm{D}$ & $\mathrm{N} / \mathrm{D}$ \\
\hline 4 & adulto & $\mathrm{N} / \mathrm{D}$ & Comp. & - & 10 & - & 6 & - & 5 & - & - & $\begin{array}{c}\text { bandas/ } \\
\text { líneas/ } \\
\text { pits }\end{array}$ & Min. \\
\hline 5 & $\begin{array}{c}\text { maduro } \\
x \\
\text { desgaste } \\
\end{array}$ & $\mathrm{N} / \mathrm{D}$ & $\begin{array}{l}1 / 2 \\
\text { Post. }\end{array}$ & - & 5 & - & 1 & - & 1 & 6 & - & $\begin{array}{l}\text { bandas } \\
\text { /pits }\end{array}$ & Medio \\
\hline 6 & adulto & $\mathrm{N} / \mathrm{D}$ & - & $1 / 2$ der. & 6 & - & 2 & - & 6 & 3 & - & defecto & Medio \\
\hline 7 & adulto & $\mathrm{N} / \mathrm{D}$ & $\begin{array}{l}\text { Frag. } \\
\text { der. }\end{array}$ & - & 5 & - & - & - & - & 3 & - & - & Medio \\
\hline 8 & $\begin{array}{l}\text { sub- } \\
\text { adulto }\end{array}$ & $\mathrm{N} / \mathrm{D}$ & - & Comp. & 14 & - & - & - & 3 & - & - & $\begin{array}{c}\text { bandas/ } \\
\text { pits }\end{array}$ & Min. \\
\hline 9 & adulto & $\mathrm{N} / \mathrm{D}$ & $\begin{array}{l}\text { Frag. } \\
\text { der. }\end{array}$ & - & 5 & - & 3 & - & 2 & 1 & - & $\begin{array}{c}\text { bandas/ } \\
\text { pits }\end{array}$ & Min. \\
\hline 10 & adulto & $\mathrm{N} / \mathrm{D}$ & $\begin{array}{l}\text { Frag. } \\
\text { der. }\end{array}$ & - & - & - & 8 & - & $\mathrm{N} / \mathrm{D}$ & $\mathrm{N} / \mathrm{D}$ & - & $\mathrm{N} / \mathrm{D}$ & $\mathrm{N} / \mathrm{D}$ \\
\hline 11 & adulto & $\mathrm{M}$ & - & Comp. & 9 & 4 & 3 & - & 8 & - & 2 PIV & $\mathrm{N} / \mathrm{D}$ & Medio \\
\hline 12 & adulto & $\mathrm{N} / \mathrm{D}$ & $\begin{array}{c}\text { Frag. } \\
\text { der }\end{array}$ & - & 3 & - & 5 & - & 1 & - & - & $\begin{array}{l}\text { mancha } \\
\text { marrón }\end{array}$ & Medio \\
\hline 13 & $\begin{array}{l}\text { adulto } \\
\text { maduro }\end{array}$ & $\mathrm{N} / \mathrm{D}$ & $\begin{array}{c}\text { Frag. } \\
\text { der }\end{array}$ & Comp. & 12 & - & 8 & - & - & $\mathrm{N} / \mathrm{D}$ & - & $\mathrm{N} / \mathrm{D}$ & Medio \\
\hline 14 & $\begin{array}{l}\text { adulto } \\
\text { maduro }\end{array}$ & $\mathrm{N} / \mathrm{D}$ & - & Comp. & 12 & 1 & 3 & - & - & - & $1 \mathrm{PIV}$ & $\begin{array}{c}\text { bandas/ } \\
\text { líneas }\end{array}$ & Medio \\
\hline 15 & $\begin{array}{l}\text { sub- } \\
\text { adulto }\end{array}$ & $\mathrm{N} / \mathrm{D}$ & Comp. & - & 8 & 2 & 2 & - & 5 & $\mathrm{~N} / \mathrm{D}$ & - & bandas & Min. \\
\hline 16 & adulto & N/D & - & Comp. & 12 & - & 4 & - & 3 & 2 & - & $\begin{array}{c}\text { líneas/ } \\
\text { pits }\end{array}$ & Min. \\
\hline 17 & adulto & $\mathrm{N} / \mathrm{D}$ & Comp. & - & 11 & - & 5 & - & 4 & - & - & $\begin{array}{c}\text { líneas/ } \\
\text { pits }\end{array}$ & Min. \\
\hline 18 & adulto & $\mathrm{N} / \mathrm{D}$ & - & $1 / 2$ der. & 3 & - & - & - & 3 & - & - & bandas & Medio \\
\hline 19 & adulto & $\mathrm{N} / \mathrm{D}$ & $\begin{array}{c}\text { Frag. } \\
\text { der }\end{array}$ & - & 4 & - & 4 & - & - & - & - & pits & Medio \\
\hline 20 & adulto & & Frag. & $\begin{array}{l}\text { Base de } \\
\text { No se lo } \\
\text { no con c }\end{array}$ & & $\begin{array}{l}\text { ura p } \\
\text { ra pa } \\
\text { xilar }\end{array}$ & $\begin{array}{l}\text { orme } \\
\text { NMI } \\
\text { xister }\end{array}$ & & $\begin{array}{l}\text { S de lo } \\
\text { esulta }\end{array}$ & $\begin{array}{l}\text { isivos } \\
\text { osible }\end{array}$ & $\begin{array}{l}\text { htrales } \\
\text { ermin }\end{array}$ & $\begin{array}{l}\text { eriores. } \\
\text { se corre }\end{array}$ & nde o \\
\hline
\end{tabular}

Tabla 5. Variables de análisis consideradas en el estudio de las piezas dentarias y su distribución según el número de individuos identificados a partir de elementos maxilares y mandíbulas. Referencias: N/D =no determinable;

Frag.=fragmento; Comp.=completo; Min: mínimo; der=derecho; ant $=$ anterior; $\mathrm{PIV}=$ piezas perdidas en vida; $\mathrm{PIM}=$ piezas perdidas postmorten . 


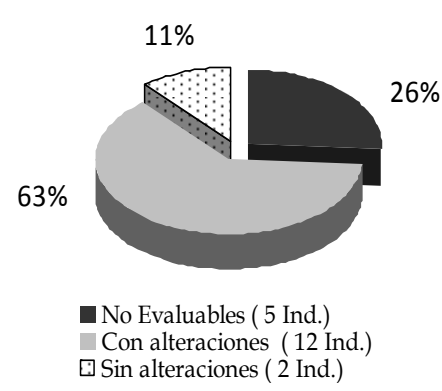

Gráfico 1: frecuencia de individuos con alteraciones amelogenéticas.

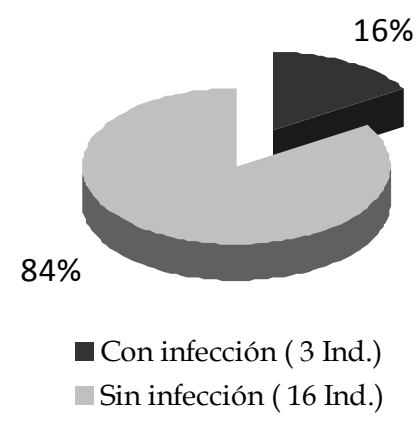

Gráfico 2: frecuencia de individuos con infección alveolar.

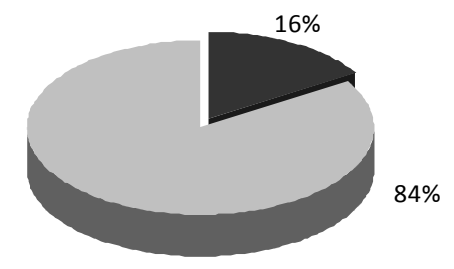

- Con PIV (3 Ind.) $\llbracket$ Sin PIV (16 Ind.)

Gráfico 3: frecuencia de individuos con pérdida de piezas en vida.

A

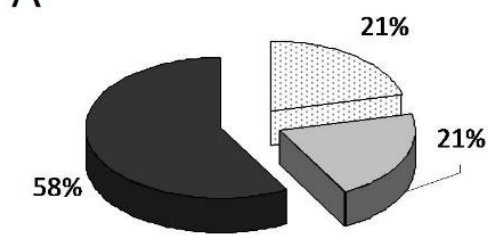

$\square$ No Evaluables (4 Ind.) $\square$ Sin patologia (4 Ind.)

- Con patologia (11 Ind.)
B

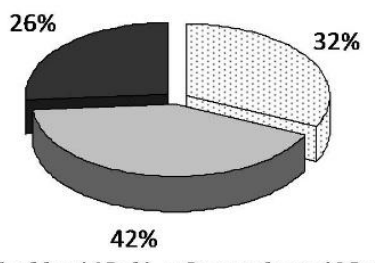

$\square$ No Evaluables (6 Ind.) $\square$ Sin patologia (8 Ind.)

- Con patologia ( 5 Ind.)

Gráfico 4: distribución de las patologías cariosas:

A) oclusal; y B) de cuello o radiculares. 
Por otra parte, en 11 piezas dentarias (58\%) se identificaron caries oclusales y en cinco $(26 \%)$ se observaron caries de cuello o radiculares. Al relacionar la variable de las patologías cariosas con la presencia de alteraciones en la amelogénesis se observa que en 10 individuos (53\%) las caries se ubican en piezas muy alteradas por la amelogénesis, lo cual indica un destacado problema de salud bucal. El análisis de las superficies masticatorias permitió establecer que el $47 \%$ de piezas dentales están medianamente desgastadas, en tanto que el 31\% presenta mínimos indicios de desgaste (Figura 5).
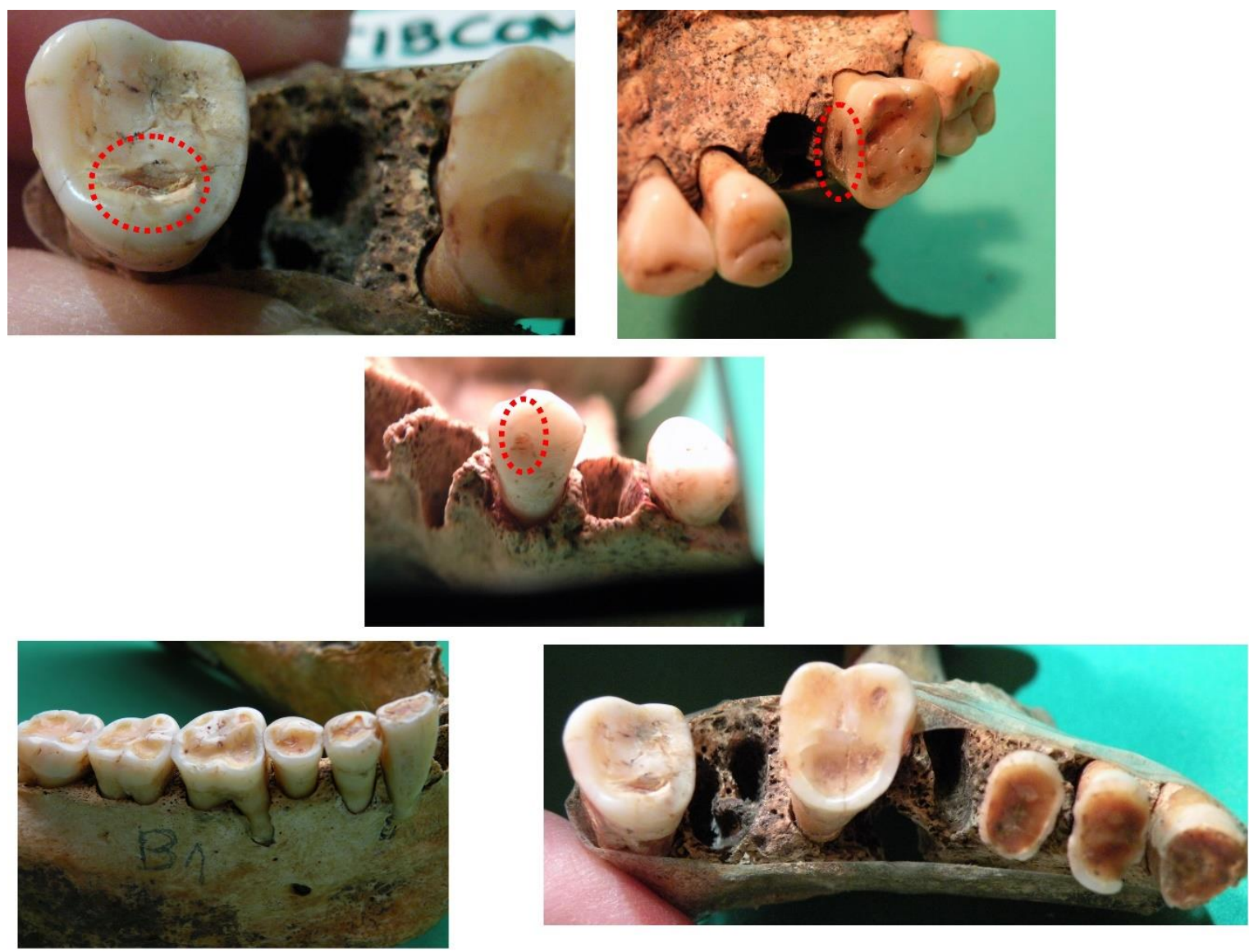

Figura 5. Arriba: caries oclusal y radicular. Centro: pit. Abajo: piezas dentales con desgaste mínimo (izquierda) y mediano (derecha).

\section{Patologías articulares y rasgos epigenéticos}

Dado que solo el $14 \%$ de piezas óseas enteras y fragmentadas del total de la muestra presenta superficies articulares, la identificación de patologías en ese sector de los elementos anatómicos es poco significativa. Las observaciones realizadas en el sector articular preservado de una vértebra cervical indican la presencia de rebordes y porosidad. También en un platillo tibial se halló la presencia de una fuerte eburnación, probablemente producida por la mayor exigencia postural en ese sector del hueso. Otro 
rasgo que consideramos de interés se vincula con la presencia del denominado torus acústico que se observa en tres de los cinco peñascos de huesos temporales que integran la muestra (Figura 6). Este es un tipo de rasgo que Neves (1988) ha calificado como epigenético y considera que se trataría de un trazo discreto no vinculado al sexo.

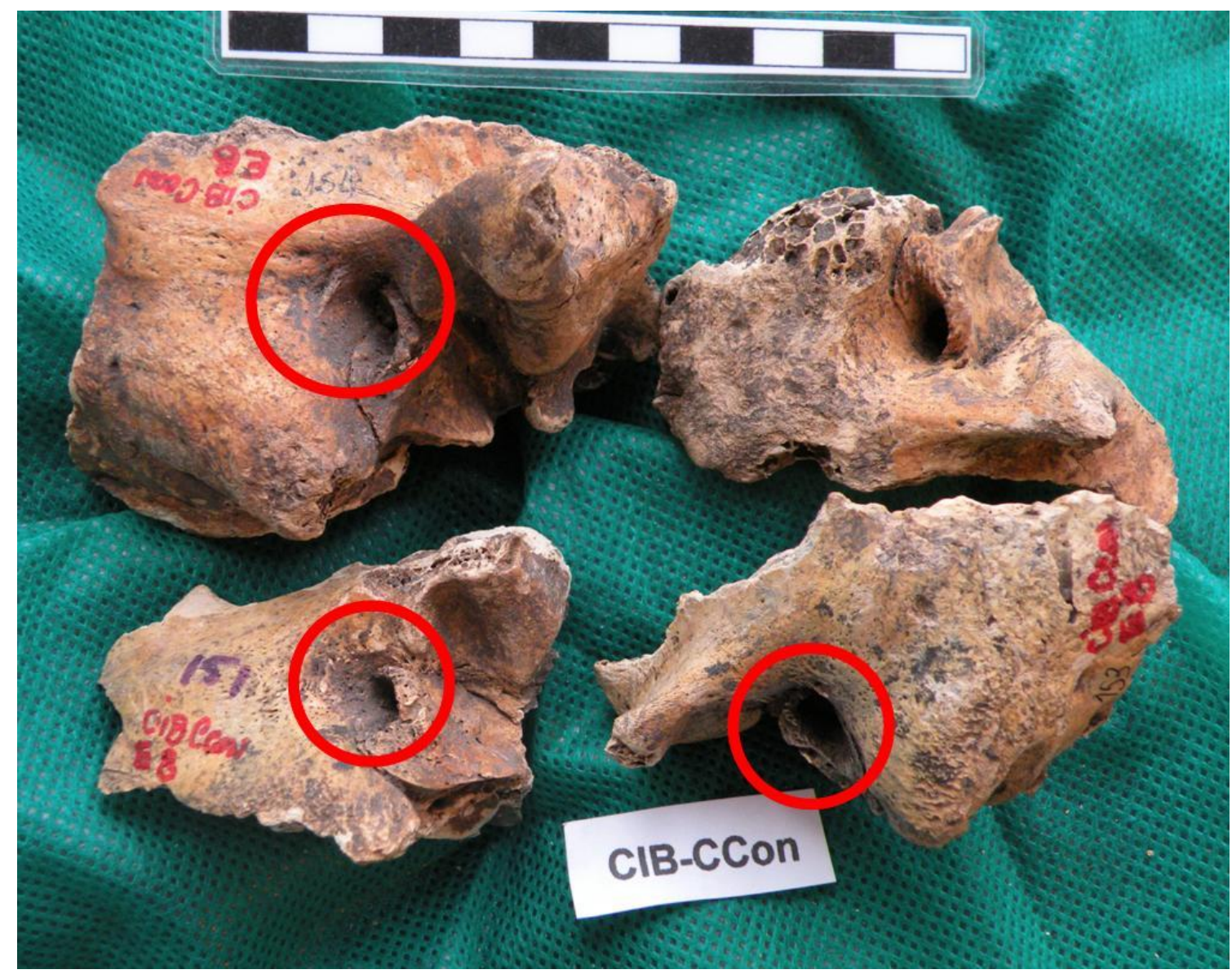

Figura 6. Torus acústico que se observa en tres peñascos de huesos temporales que integran la muestra.

\section{Discusión}

Aunque el material disponible es incompleto y fragmentario, el estudio de los maxilares, mandíbulas y las piezas dentarias permitió ampliar la determinación previamente realizada sobre la existencia de patologías cariosas e hipoplasias producidas en el esmalte durante la amelogénesis (Tapia 2002). Al respecto se observa un elevado porcentaje de patologías en el esmalte dentario, entre ellas hipoplasias y pitting (63\%) y caries (84\%). La relación entre ambos tipos de rasgos puede considerarse un indicador de la existencia de procesos metabólicos de deficiencia nutricional y de marcada descalcificación producida durante la amelogénesis. Esta información puede 
correlacionarse con los datos que proporcionan las fuentes documentales, que refieren hambrunas y epidemias muy frecuentes entre las poblaciones reducidas en la Misión de Baradero y que fueron escritas durante el rango temporal delimitado por los fechados radiocarbónicos obtenidos (AGI-ACH 1619, 1620, 1622, 1679; Tapia 2002).

La presencia de manchas de ocre sobre las piezas esqueletales se ha observado en los restos óseos de diferentes sitios prehistóricos del área y se ha vinculado con la práctica mortuoria de pintar los cuerpos con pigmentos preparados con óxidos ferrosos, antes de que los individuos fuesen enterrados (Loponte et al. 2011) o bien sobre los huesos descarnados en el caso de enterratorios secundarios. La presencia de este rasgo sobre una tibia y un húmero en el sitio Cementerio Indígena, vinculado con los tiempos en que se desarrolló la acción evangelizadora de la misión franciscana, constituye un indicador de la continuidad de esa práctica mortuoria indígena prehispánica. Si bien se observaban cambios en la posición de entierro tradicional (de cúbito dorsal con extremidades flexionadas o enterratorios en urna), por la colocación del cuerpo extendido inculcado por la doctrina cristiana, los hallazgos asociados muestran la persistencia de prácticas indígenas y de una cosmovisión del mundo no occidental; por ejemplo, el cuidado en la preparación del cuerpo para su rito de pasaje cubriéndolo con ocre.

En escala regional los rasgos epigenéticos contribuyen problemas a resolver de relaciones biológicas inter e intra poblacionales y cambios en las formas de subsistencia, tanto en contextos culturales prehistóricos como históricos. En escala local, el caso del torus acústico reviste especial interés por cuanto se lo ha vinculado con la presencia de exostosis auditiva, un posible marcador de actividades que implican la inmersión para la pesca, recolección de moluscos en aguas profundas o natación. Según Pezo Lanfranco et al. (2009) la exostosis auditiva es una hiperplasia ósea benigna morfológicamente ovoide, de base ancha o pedunculada, que aparece en el tracto medio o en la entrada del conducto auditivo externo. La forma, volumen, número, localización en el conducto y materialidad de las lesiones es muy variable incluso a nivel individual. En un estudio realizado sobre 256 cráneos, que corresponden a colecciones de restos esqueletarios prehispánicos hallados en varios sitos del Delta del Paraná y del río Paraná Inferior, Mazza (2013) ha identificado rasgos de exostosis auditiva en algunos individuos aunque en una baja frecuencia. En el caso de los individuos del Cementerio Indígena de Baradero, lamentablemente, dado que su número es escaso resulta aventurado plantear una discusión al respecto y realizar inferencias sobre su relación con el tipo de actividades, la división social del trabajo, etc.

Si bien aún se debe obtener información de un mayor número de muestras de ADNmt que corroboren y amplíen los resultados obtenidos hasta el momento, surge $a$ priori el interrogante acerca de si algunos de los marcadores genéticos identificados podría estar vinculado con la presencia de materiales arqueológicos foráneos, como los 
discos de latón con decoración punzonada perimetral, que se encuentran en el registro funerario del Cementerio Indígena. De acuerdo con las referencias de las fuentes escritas, podría ser posible que algunos individuos de origen andino, que merodeaban en las pampas buscando ganado, hayan sido relocalizados en la misión Santiago del Baradero, políticas de reducción muy generalizadas en diferentes situaciones de dominación colonial (AGI-ACH 1628, 1664, 1678; Lightfoot 2005; Stein 2005). Por el momento, esta vía de análisis queda abierta para indagaciones arqueológicas futuras sobre las relaciones interétnicas y los procesos de etnogénesis en escala local y regional.

\section{Comentarios finales}

Los objetivos planteados en este trabajo se han focalizado en la caracterización bioantropológica de un conjunto de restos óseos muy fragmentados, cuya ubicación cronológica y procedencia cultural permite considerarlos de singular importancia, a juzgar por la escasez de registros arqueológicos contemporáneos similares en el área de estudio. Si bien se trata de una muestra que procede de una colección museográfica del sitio y de diversos restos craneales y postcraneales que no presentan integridad, la determinación de un número mínimo de 19 individuos correspondientes a diferentes franjas etarias, además de un individuo perinato, proporciona información de utilidad para responder a algunas cuestiones de abordaje interdisciplinario planteadas inicialmente.

Dado que los materiales del Cementerio Indígena constituyen una de las pocas evidencias arqueológicas que existen de las primeras misiones franciscanas asentadas en el Paraná Inferior y el Río de La Plata en el siglo XVII, se espera seguir profundizado el análisis bioarqueológico de los restos óseos humanos y abrir nuevas líneas de investigación sobre las consecuencias biológicas y culturales de la conquista en el área. Por un lado, se espera profundizar el análisis del rasgo identificado en el torus auditivo para comparar con otros casos referidos para el área y discutir acerca de si puede considerarse como epigenético -que refleja algún grado de similaridad genética entre individuos o grupo de individuos- o bien si se trata de un rasgo adquirido por la práctica frecuente de actividades culturales similares (Mazza 2013; Pezo Lanfranco et al. 2009). Tal tipo de cuestiones estimula a profundizar la búsqueda de éste $\mathrm{u}$ otros rasgos similares. Por otra parte se espera continuar avanzando con el estudio de los marcadores genéticos, otra de las vías de investigación que a futuro puede proporcionar información significativa sobre las consecuencias biológicas y culturales de la empresa colonial entre los nativos del Paraná Inferior. 


\section{Notas}

1 Si bien la materia prima con la cual fueron confeccionados los discos y las cuentas corresponde al latón -cuya fabricación se vincula con la presencia hispánica dado que no fue elaborado por los metalurgistas americanos- se incluyen en este grupo porque presentan una morfología y una decoración típica de la tradición indígena (Tapia et al. 2009).

2 En el año 2006 el sitio Cementerio Indígena fue declarado Patrimonio Arqueológico e Histórico por ordenanza del municipio de Baradero. Al año siguiente se inició la elaboración de un Proyecto de Museo de sitio y de un Centro de Interpretación, en conjunto con agrupaciones mapuches de la provincia de Buenos Aires, tobas de San Pedro y huarpes de San Juan, que habían reclamado participar en la toma de decisiones sobre el sitio. En 2008 se efectuó una jornada de evaluación del proyecto con la participación de grupos originarios, autoridades, vecinos e investigadores y se firmó un acta de acuerdo para la ejecución del mismo.

3 Proyectos de investigación subsidiados por la Secretaria de Ciencia y Técnica de la Universidad Nacional de Luján (Programaciones científicas 2006-2008, 2009-2010, 20112014) y por Foncyt-Pict 2008-1981.

${ }^{4}$ Se denomina amelogénesis al proceso de formación del esmalte dental producido por células llamadas ameloblastos. Durante dicho proceso, ya sea tanto por factores genéticos como ambientales, pueden aparecer anomalías en la superficie del esmalte principalmente en forma de pitting o pequeñas depresiones y de hipoplasias de esmalte o surcos marcados en la corona de manera paralela a la cara oclusal. En la corona también pueden aparecer líneas de coloración más clara que el resto del esmalte, alteración conocida con el nombre de líneas de hipocalcificación (White y Folkens 1991).

\section{Bibliografía citada}

Baffi, I y M. Torres

1995-96 Los restos óseos humanos del sitio Martínez 4 (Ambato, Catamarca). Publicaciones Arqueología 48: 55-64.

Barbich, J.

2007 Historia de Santiago del Baradero. Editorial Amerindia, Buenos Aires.

Behrensmeyer, A.

1978 Taphonomic and ecologic information from bone weathering. Paleobiology 4: 150162. 
Blumenschine, R.; Marean, C. y S. Capaldo

1996 Blind test of inter-analyst correspondence and accuracy in the identification of cut marks, percussion marks, and carnivore tooth mark of bone surface. Journal of Archaeological Science 23: 493-507.

Brothwell, D.

1993 Desenterrando Huesos. La Excavación, Tratamiento y Estudio de Restos del Esqueleto Humano. Fondo de Cultura Económica, Madrid.

Buikstra, J. y D. Ubelaker

1994 Standards for Data Collection from Human Skeletal Remains. Arkansas Archaeological Survey, Research Series n ${ }^{\circ} 44$. Faytteville, Arkansas.

Cardozo, D.; Crespo, C.; Russo, G. y M. Postillone

2014 Análisis de ADN antiguo en restos esqueletales humanos de sitios arqueológicos y colecciones de museos. IX Jornadas de Jóvenes Investigadores en Ciencias Antropológicas. INAPL, Buenos Aires. En prensa.

Cardozo, D.; Dejean, C.; Tapia, A. y L. Kozameh

2013 Caracterización genética de restos óseos de poblaciones pre y post hispánicas del Paraná Inferior. XVIII Congreso Nacional de Arqueología Argentina. Universidad Nacional de La Rioja, La Rioja.

Conlazo, D.

1984 Ficha de Ingreso Museográfico de la Colección de Restos Óseos del Sitio Cementerio Indígena. Museo Histórico Alejandro Barbich, Baradero. Manuscrito.

Debenedetti, S.

1911 Noticia sobre un cementerio indígena de Baradero. Revista de la Universidad de Buenos Aires, Publicaciones de la Sección Antropológica, tomo XIII 9: 435-448.

Fasekas, I. y F. Kósa

1978 Forensic Fetal Osteology. Akadémiai Kiadó, Budapest.

Lightfoot, $\mathrm{K}$.

2005 Indians, Missionaries, and Mechants. The Legacy of Colonial Encounters on the California Frontiers. University of California Press, Berkeley.

Loponte, D.; Acosta, A.; Capparelli, I. y M. Pérez

2011 La arqueología guaraní en el extremo meridional de la Cuenca del Plata. En Arqueología Tupíguaraní, D. Loponte y A. Acosta (eds.), pp. 111-154. Instituto Nacional de Antropología y Pensamiento Latinoamericano, Buenos Aires. 
Lovejoy, C.

1985 Dental wear in the Libben population: its functional pattern and role in the determination of adult skeletal age at death. American Journal of Physical Anrthopology 68: 47-56.

Luna, L.

2002 Análisis de restos óseos humanos fragmentados procedentes de una estructura funeraria compleja: sitio Chenque 1 (Parque Nacional Lihué Calel, Provincia de La Pampa). Relaciones de la Sociedad Argentina de Antropología XXVII: 145-161

2008. Estructura Demográfica, Estilo de Vida y Relaciones Biológicas de Cazadores Recolectores en un Ambiente de Desierto. Sitio Chenque 1 (Parque Nacional Lihué Calel, Provincia de La Pampa, Argentina). BAR International Series 1886, Oxford.

Mays, S.; De la Rua, C. y T. Molleson

1995 Molar crown height as a means of evaluating existing dental wear scales for estimating age at death in human skeletal remains. Journal of Archaeological Science 22: 659-670.

Mazza, B.

2013 Marcadores óseos de actividad acuática en poblaciones prehispánicas del humedal del Paraná Inferior: la exostosis auditiva como caso de estudio. XI Jornadas Nacionales de Antropología Biológica. Universidad Maimónides, Buenos Aires.

McKinley, J.

2004a Compiling a skeletal inventory; cremated human bone. En Guidelines to the Standards for Recording Human Remains, M. Brickley y J. McKinley (eds.), pp. 9-13. Institute of Field Archaeologists, Paper 7. University of Southampton, Southampton. 2004b Compiling a skeletal inventory: disarticulated and co-mingled remains. En Guidelines to the Standards for Recording Human Remains, M. Brickley y J. McKinley (eds.), pp. 14-17. Institute of Field Archaeologists, Paper 7. University of Southampton, Southhampton.

Neves, W.

1988 Paleogenética dos grupos pré-históricos do litoral sul do Brasil (Paraná e Santa Catarina). Pesquisas (Antropologia) 43. Instituto Anchietano de Pesquisas.

Pezo Lanfranco, L.; Pezo Lanfranco, S. y S. Eggers

2009 Exostosis auditiva como marcador osteológico de actividad acuática en poblaciones formativas de la Costa Norte del Perú. Paleopatología-AEP 6: 2-18. 
Pifferetti, A.

2001 Algunos casos de corrosión por terrenos en aleaciones de cobre de origen arqueológico. Jornadas SAM-CONAMET-AAS, Posadas.

Salgán, L.; Tucker, H.; Luna, L.; Aranda, C. y A. Gil

2012 Estudios arqueológicos y bioarqueológicos en la cuenca media del río Malargüe (provincia de Mendoza): el sitio Bajada de las Tropas 1. Relaciones de la Sociedad Argentina de Antropología XXXVII(1): 113-135.

Santini, A. ; Land, M. y G. Raab

1990 The accuracy of simple ordinal scoring of tooth attrition in age assessment. Forensic Science International 48: 175-184.

Stein, G.

2005 The Archaeology of Colonial Encounter. Comparative Perspectives. School of American Research Press, New México.

Tapia, A.

1999 Visibilidad arqueológica de la conquista en la cuenca del Paraná-Plata. En Arqueología y Bioantropología de las Tierras Bajas, J. López Mazz y M. Sans (eds.), pp.147164. Universidad de la República, Montevideo.

2002 Indicadores biológicos y culturales de la conquista en el Delta del Paraná (siglos XVI y XVII). Relaciones de la Sociedad Argentina de Antropología XXVII: 357-374.

Tapia, A. y V. Pineau

2011 Diversidad de las cuentas de vidrio. El caso de Santiago del Baradero (siglo XVII). Arqueología 17: 119-136.

2013 Tipología, manufactura y procedencia de las cuentas vítreas de Santiago del Baradero. Cuadernos del INAPL, Series especiales 1(3): 105-120.

Tapia, A.; Landa, C.; De Rosa, H. y E. Montanari

2009 Artefactos metálicos de las inhumaciones del Cementerio Indígena de Baradero. Arqueometría Latinoamericana. 2do Congreso Argentino, 1ero Latinoamericano I: 263-269. Comisión Nacional de Energía Atómica, Buenos Aires.

Ubelaker, D.

1974 Reconstruction of Demographic Profiles from Ossuary Skeletal Samples. A Case Study from the Tidewater Potomac. Smithsonian Contributions to Anthropology 18. Smithsonian Institution Press, Washington. 
Ubelaker, D. y C. Ripley

1999 The Ossuary of San Francisco Church, Quito, Ecuador: Human Skeletal Biology. Smithsonian Contributions to Anthropology 42. Smithsonian Institution Press, Washington.

White, T. y P. Folkens

1991 Human Osteology. Academic Press, San Francisco.

Fuentes de Archivo

Archivo General de Indias, Audiencia de Charcas. Repositorio del Museo Etnográfico (MET cajas B, C, E, F, H, I, J):

- 1606. Leg 145. Carta al Rey de España de Fray Baltazar Navarro, 21 de febrero de 1606, MET B 8.

- 1609. Legajo 27. Hernandarias de Saavedra, Carta al Rey de España, 8 de mayo de 1609, MET B 11.

- 1610. Leg. 27. Diego Marín Negrón, Carta al Rey de España, 30 de abril de 1610, MET B 12.

- 1613. Leg 112. Diego Marín Negrón. Carta al Rey de España, detalla la situación en el Río de la Plata 31 de mayo de 1613, MET B 15.

- 1616. Leg. 27. Hernandarias de Saavedra. Carta al Rey de España, informe de visita a reducciones, 25 de mayo de 1616, MET B 16.

- 1617. Leg. 147. Fray Bartolomé de la Madalena, Información de méritos y servicios de la Orden de San Francisco. 5 al 13 de julio de 1617, MET B 17.

- 1618. Leg. 12. Hernandarias de Saavedra, Carta al Rey de España, informe de los años de gobierno, 13 de mayo de 1618, MET C 3.

- 1619-20. Legajo 27, Cartas del Gobernador Diego de Góngora al Rey de España del 20 de julio de 1619 y del 2 de marzo de 1620, MET C 8.

- 1622. Legajo 27, Relación de lo hecho por el gobernador Don Diego de Góngora en visita general que hizo de las Provincias del Río de la Plata, MET C 14.

- 1628. Legajo 28, Francisco de Céspedes, corregidores de las reducciones, MET C 20.

- 1664. Legajo 139, C. Mancha y Velazco, Carta al Rey de España, MET E 10.

- 1678. Legajo 283, Andrés Robles, Carta al Rey de España, MET F 6.

- 1678. Legajo 9, Antonio Azcona Imbert, Carta al Rey de España, MET F 7.

- 1679. Legajo 3, Carlos II, Carta al Obispo de Buenos Aires sobre situación de indígenas sometidos, MET F 14.

- 1690. Legajo 282, J. Herrera y Sotomayor, Carta al Rey de España. Expediente iniciado el 28 de abril de 1690 sobre reducción de chanáes en Santiago del Baradero, MET H2.

- 1691. Legajo 4. Carlos II, Carta al Gobernador Agustín Robles sobre la reducción de chanáes de Baradero, 25 de marzo de 1691, MET H 5.

- 1694. Legajo 4. Carlos II, Carta al Gobernador sobre tributos y diezmos en las reducciones, 15 de octubre de 1694, MET H 6. 